\title{
Psychoactive drug prescribing by Dutch child and adolescent psychiatrists
}

\author{
JACQUELINE G. HUGTENBURG ${ }^{1}$, EIBERT R. HEERDINK ${ }^{1} \& \mathrm{YUNG}^{\mathrm{H}} \mathrm{HWO}_{\mathrm{TSO}}^{2}$ \\ ${ }^{1}$ Utrecht Institute for Pharmaceutical Sciences, Department of Pharmacoepidemiology E Pharmacotherapy, Utrecht University, \\ Utrecht, The Netherlands, and ${ }^{2}$ Practice for Child and Adolescent Psychiatry, Amstelveen, The Netherlands
}

\begin{abstract}
Aim: To gain more insight into the prescribing of psychoactive drugs by Dutch child psychiatrists. Methods: A questionnaire was sent to all child psychiatrists in the Netherlands. Questions were asked about the prescribing of antidepressants, antipsychotics, anxiolytics and psychostimulants for psychiatric disorders in children. Results: The preference of specific antidepressants, antipsychotics and anxiolytics depends on the disorder. For different disorders, off-label prescribing varies from 19 to $71 \%$.
\end{abstract}

Conclusion: Preferences differ widely. Off-label drug prescribing is high. More studies on the efficacy and safety of psychoactive drugs in children are therefore required.

Key Words: Child psychiatrists, prescribing of psychoactive drugs, off-label use, questionnaire, children

\section{Introduction}

In the past decade the use of psychoactive drugs by children has sharply increased in Western countries [1-3]. Since only limited data of the effects of psychoactive drugs in daily practice are available and possible long-term adverse effects are not known, the increased use of psychoactive drugs has resulted in public concern. Moreover, uncertainty about the disorders and symptoms for which these drugs are prescribed has contributed to this concern. Studies on the consumption of psychoactive drugs by children are generally limited to the estimation of incidences and prevalences based on pharmacy medication records or data from insurance companies.

A recent Australian study of drug prescribing by child psychiatrists and child physicians showed that they prescribed a wide range of drugs for children [4]. Off-label use amounted to about $40 \%$. However, at present there are only limited data on the efficacy and safety of psychoactive drugs in children.

It was the aim of the present study to gain more insight into psychoactive drug prescribing by Dutch child psychiatrists.

\section{Methods}

A questionnaire was sent to all 316 Dutch child psychiatrists registered with the Department of Child and Adolescent Psychiatry of the Dutch Society for Psychiatry in May-June 2001. After 1 mo, they received a reminder. The concept of the questionnaire was discussed with five child psychiatrists. Suggestions for changes were considered. The questionnaire was tested in a pilot study among 20 child psychiatrists.

(1) The questionnaire contained general questions about the child psychiatrists and their practices. The child psychiatrists were asked whether drug treatment was an important element of the treatment of $\mathrm{ADHD}$, depressive disorder, anxiety disorder, autism and obsessive compulsive disorder (OCD).

(2) The child psychiatrists were asked which antidepressant they would use for the treatment of disorders that may be treated with antidepressants. This same question was asked for disorders that may be treated with antipsychotics and anxiolytics.

Correspondence: Jacqueline G. Hugtenburg, Utrecht Institute for Pharmaceutical Sciences, Department of Pharmacoepidemiology \& Pharmacotherapy, Box 80082, 3508 TB Utrecht, The Netherlands. Tel: + 31030 2537324. Fax: + 31030 2539166. E-mail: j.g.hugtenburg@pharm.uu.nl 

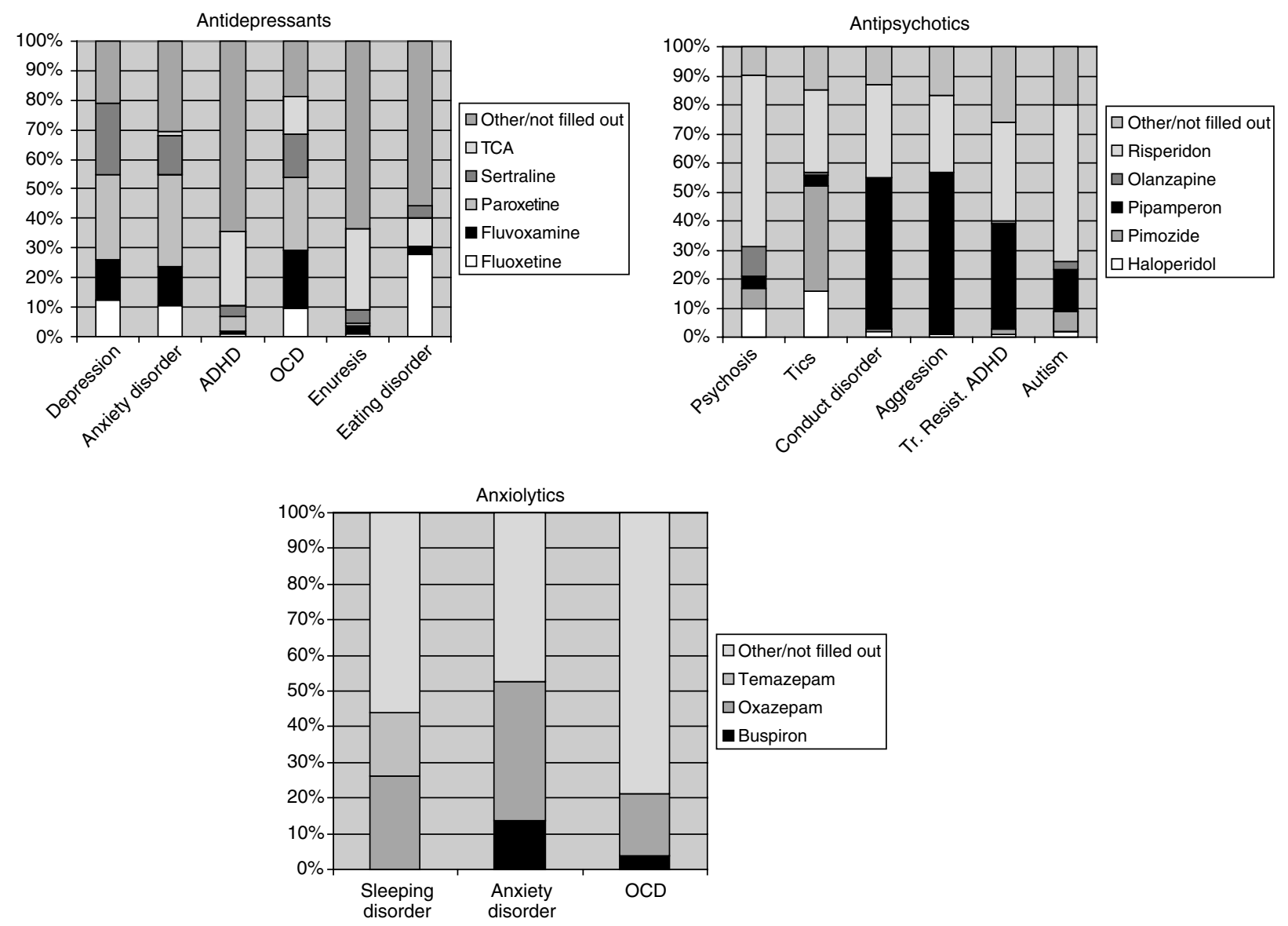

Figure 1. Percentage of child psychiatrists that prefers a specific (a) antidepressant, (b) antipsychotic or (c) anxiolytic drug for the treatment of the disorders mentioned.

(3) Questions were asked about the off-label prescribing of antidepressants, antipsychotics and anxiolytics.

Data were collected in SPSS 10.0. Calculation of frequencies was used to describe data on drug prescribing.

\section{Results}

Response and basic data of the child psychiatrists

One hundred and forty (44.3\%) of 316 questionnaires were returned. Twenty-five respondents did not complete the questionnaire because they were retired or for any other reason no longer active as child psychiatrists. A study on the child psychiatrists registered revealed that a further 37 non-respondents were also no longer active as child psychiatrists. As a consequence, 115 of 254 (45.2\%) questionnaires were evaluated.

The setting of the child psychiatrists was as follows: independent $23 \%$, academic hospital $10 \%$, ambulatory academic hospital $19 \%$, peripheral hospital $21 \%$, ambulatory peripheral hospital $29 \%$, institution $20 \%$, and other $31 \%$.

\section{Psychoactive drug treatment and importance of drug treatment}

For the treatment of ADHD, pharmacotherapy was considered important or very important by $91.3 \%$. For OCD, depressive disorder, anxiety disorder and autism, these figures amounted to $67.0 \%, 65.8 \%$, $30.1 \%$ and $28.9 \%$, respectively.

\section{Choice of antidepressants, antipsychotics and anxiolytics}

Figure 1 shows which psychoactive drugs were preferred for the treatment of diseases which may be treated with a psychoactive drug. More child psychiatrists reported to have a preference for paroxetine than for the other antidepressants for the treatment of depressive disorders. Depending on the disorder, haloperidol, pimozide, risperidone or pipamperone were preferred when an antipsychotic drug was prescribed. When an anxiolytic drug was prescribed for the treatment of a sleeping disorder, primarily oxazepam and temazepam were chosen. 
Off-label use of antidepressants, anxiolytics, psychostimulants and anxiolytics

In addition to depression, anxiety disorder and OCD, $82(71.3 \%)$ of the child psychiatrists also used antidepressants for disorders such as ADHD, autism, aggression and eating disorder.

Twenty-two (19.1\%) reported prescribing antipsychotics for disorders other than those mentioned in Figure 1. These included sleeping disorder, eating disorder, impulse-control disorder not elsewhere classified, OCD and delirium.

In addition to ADHD and learning disorder, 29 $(25.2 \%)$ of the child psychiatrists also prescribed psychostimulants for the treatment of autism, ADHD as co-morbidity, depression, enuresis and conduct disorder.

In addition to anxiety disorder, OCD and sleeping disorder, $34(29.6 \%)$ of the child psychiatrists also used anxiolytics for the treatment of psychosis, autism, aggression, panic disorder, and impulse-control disorder not elsewhere classified.

\section{Discussion}

The results of the study show that Dutch child psychiatrists frequently prescribe psychoactive drugs off-label. The off-label prescribing of psychoactive drugs is based both on the expertise of the child psychiatrists and the proven efficacy of these drugs in adults (analogy-based use). It may occur more or less routinely (expertise-based use) or as a try-out when other drugs are not effective. Based on an Australian study, Efron and co-workers [4] also reported a high level of off-label prescribing of psychoactive drugs for children.

For the treatment of psychosis and autism, child psychiatrists preferred risperidone. The prescribing of this drug seems based only on the results of small, open studies $[5,6]$. However, recently a randomized, double-blind study indeed showed risperidone to be effective in children suffering from psychosis [7]. In 2002 the effectiveness in the treatment of behavioural symptoms in children with autism was also shown in a randomized, double-blind study [8]. A large part of the respondents prescribes haloperidol for the treatment of tics. Several placebo-controlled studies showed that both risperidone and haloperidol were effective in children [9-11]. The majority of the child psychiatrists preferred imipramine for the treatment of enuresis. This finding is in accordance with the efficacy of this drug shown in a number of studies [12].

In contrast, for the prescribing of a number of drugs, including buspiron, pipamperone and risperidone, for tics and treatment-resistant ADHD, studies supporting the use of these drugs in children are not available.
As a result of the large consumption of paroxetine by adults, a quarter to one-third of the child psychiatrists reported preferring the selective serotonin reuptake inhibitor (SSRI) paroxetine for the treatment of depressive disorder, anxiety disorder and OCD [13]. Recent warnings against the use of SSRIs and serotonin norepinephrine reuptake inhibitors (SNRIs) in children because of an increased risk of suicide show that the use of these psychoactive drugs in children may be accompanied by unknown risks. The prescribing of fluvoxamine for the treatment of eating disorder also seems to result from its effectiveness in adults [14]. The prescribing of temazepam for the treatment of sleeping disorder also seems based largely on the use of this drug for the treatment of sleeping disorder in adult patients. An evaluation of prescribing practices in Britain and a prospective study on the incidence of psychoactive drug prescribing for children have also shown that a wide range of drugs for a large number of conditions are prescribed $[15,16]$.

\section{Limitations}

The use of a questionnaire may have resulted in socially desirable answers. In addition, it is difficult to get a very precise insight into off-label prescribing since, from some groups of drugs, only certain drugs are licensed for only certain diseases in children, e.g. haloperidol for psychosis. In addition, it is not clear whether a drug is prescribed for the treatment of a symptom, such as compulsive disorder in autism, rather than for the primary disorder.

\section{Conclusion}

Because of lack of sufficient data on the efficacy and safety of psychoactive drugs in children, the extent of off-label psychoactive drug prescribing gives considerable cause for concern. To improve this situation, more studies of the efficacy and safety of psychoactive drugs in children should be performed. In addition, a study of how child and adolescent psychiatrists prescribe drugs is required.

\section{Acknowledgement}

The authors acknowledge the Department of Child Psychiatry of the Dutch Society for Psychiatry for providing the addresses of Dutch child and adolescent psychiatrists.

\section{References}

[1] Safer DJ, Zito JM, Fine EM. Increased methylphenidate usage for attention deficit disorder in the 1990s. Pediatrics 1996;98:1084-8.

[2] Zwi M, Ramchandani P, Joughin C. Evidence and belief in ADHD. Br Med J 2000;321:975-6.

[3] Schirm E, Tobi H, Zito JM, De Jong-van den Berg LT. Psychotropic medication in children: A study from the Netherlands. Pediatrics 2001;108:e25. 
[4] Efron D, Hiscock H, Sewell JR, Cranswick WE, Vance AL, Tyl Y, et al. Prescribing of psychotropic medications for children by Australian pediatricians and child psychiatrists. Pediatrics 2003;11:372-5.

[5] Masi G, Cosenza A, Mucci M, De Vito G. Risperidone monotherapy in preschool children with pervasive developmental disorders. J Child Neurol 2001;16:395-400.

[6] Vercellino F, Zanotto E, Ravera G, Veneselli E. Open-label risperidone treatment of 6 children and adolescents with autism. Can J Psychiatry 2001;46:559-60.

[7] Sikich L, Hamer RM, Bashford RA, Sheitman BB, Lieberman JA. A pilot study of risperidone, olanzapine, and haloperidol in psychotic youth: A double-blind, randomized, 8-week trial. Neuropsychopharmacol 2003; DOI: 10.1038/ sj.npp.1300327.

[8] McCracken JT, McGough J, Shah B, Cronin P, Hong D, Aman $\mathrm{MG}$, et al. Risperidone in children with autism and serious behavioural problems. New Engl J Med 2002;347:314-21.

[9] Bruggeman R, Van der Linden C, Buitelaar JK, Gericke GS, Hawkridge SM, Temlett JA. Risperidone versus pimozide in Tourette's disorder: a comparative double-blind parallel-group study. J Clin Psychiatry 2001;62:50-6.
[10] Dion Y, Annable L, Sandor P, Chouinard G. Risperidone in the treatment of Tourette syndrome: a double-blind, placebocontrolled trial. J Clin Psychopharmacol 2002;22:31-9.

[11] Scahill L, Leckman JF, Schultz RT, Katsovich L, Pederson BS. A placebo-controlled trial of risperidone in Tourette syndrome. Neurology 2003;60:1130-5.

[12] Glazener CM, Evans JH, Peto RE. Tricyclic and related drugs for nocturnal enuresis in children. Cochrane Database Syst Rev 2003; (3):CD002117.

[13] Pathiyal A, Hylan TR, Jones JK, Davtian D, Sverdlov L, Keyser M. Prescribing of selective serotonin reuptake inhibitors, anxiolytics, and sedative-hypnotics by general practitioners in The Netherlands: a multivariate analysis. Clin Ther 1997; 19:798-810.

[14] Kim SS. Role of fluoxetine in anorexia nervosa. Ann Pharmacother 2003;37:890-2.

[15] Bramble D. Annotation: The use of psychotropic medications in children: a British view. J Child Psychol Psychiatry 2003;44:169-79.

[16] Clark AF. Incidences of new prescribing by British child and adolescent psychiatrists: a prospective study over 12 months. J Psychopharmacol 2004;18:115-20. 